\title{
EL APANDO Y LA PUESTA EN CRISIS NOVELESCA Y FÍLMICA DE LA RACIONALIDAD OCCIDENTAL COMO DENUNCIA DEL SISTEMA SOCIAL ${ }^{1}$
}

\author{
Darcie Doll \\ Universidad de Chile \\ darciedoll.cecla@gmail.com

\section{RESUMEN / ABSTRACT}

El artículo propone que en las dos versiones de El Apando, la novela y el filme, se exhibe una puesta en crisis de los fundamentos de la racionalidad y sus correlatos totalizadores desde varios frentes: la escenificación de la perspectiva óptica del sujeto geometral, la crítica del discurso tradicional de la nación y el planteamiento del encierro carcelario como extensión de la cárcel que es el mundo. A través de diversas estrategias discursivas se produce una subversión de los códigos realistas, en el marco de una denuncia de la opresión y la violencia del sistema social contemporáneo. Los relatos nos introducen en lo que será, décadas más tarde, la representación del mundo del narcotráfico y las consecuencias de la globalización económica en América Latina.

PALABRAS CLAVE: cine latinoamericano, narrativa latinoamericana, realismo.

The article proposes that in the two versions of The Apando, both novel and film, a moment of crisis of the fundaments of rationality and its totalizing correlates are being displayed from different angles: the staging of the optic perspective of the geometral individual, the critic of de traditional discourse of the nation, and the approach of the prisoned confinement as an extension of the prison that the world is. Through diverse discursive strategies it is produced a subversion of realistic codes, in the frame of a denunciation of the oppression and the violence of the contemporary social system. The stories introduce us in to what will

1 Este artículo formó parte de una investigación titulada: “¿Hacia un 'nuevo realismo'? Representación de la marginalidad y lo urbano en un sector del cine y la narrativa latinoamericana 1990-2008". Proyecto de Ciencias Sociales, Humanidades y Educación. Vicerrectoría de Investigación y Desarrollo. Universidad de Chile. 
be, decades later, the representation of the drug trafficking world and the consequences of economic globalization in Latin America.

KEYWORDS: Latin-American cinema, Latin-American narrative, realism.

(Revueltas y Agustín) coinciden en una visión que yo comparto a fondo: que la única realidad posible, en esas circunstancias, es esa; al menos de que cambie todo.

(Felipe Cazals)

\section{INTRODUCCIÓN}

A partir de la década de los noventa se realiza una serie de filmes y novelas en diversos países latinoamericanos que ha sido asociadas a la emergencia de un "nuevo realismo", también denominado "realismo sucio", "realismo de la marginalidad", "realismo urbano", "nuevo cine", "narconovela", entre otros rótulos. Desde diferentes estrategias constructivas y perspectivas, estos relatos comparten la crítica y denuncia de la violencia, la marginalidad urbana y el narcotráfico. En esta confluencia entre cine y literatura destacan La virgen de los sicarios, Rosario Tijeras, Carandiru, entre otros textos que son comparables y asociables como parte de una tendencia. Estas nuevas prácticas mantienen un interesante diálogo tanto con el cine como con la literatura latinoamericana de las décadas anteriores, especialmente respecto de las formas de representación de la marginalidad y la violencia. En ese sentido es que El Apando (1969), novela corta de José Revueltas², y El apando

2 José Revueltas fue novelista, cuentista, dramaturgo, periodista, ensayista, argumentista y guionista. Nació en 1914 y murió en 1976. Fue encarcelado varias veces en su vida, la primera, a los 16 años. Entre 1968 y 1971 estuvo preso debido a su activa participación en el Movimiento Estudiantil del 68 en México, en la cárcel de Lecumberri, conocida como "El palacio negro". En el ámbito del cine, se desempeñó especialmente como guionista. En 1944, Gabriel Figueroa lo invita a trabajar en la adaptación de El mexicano, de Jack London. Otras adaptaciones fueron Cantaclaro, de Rómulo Gallegos; La Otra, de Ryan James, Que dios me perdone, de Xavier Villaurrutia, La ilusión viaja en tranvía. Es autor de las novelas: Los muros del agua (1941), El luto humano (1943), Los días terrenales (1949), En algún valle de lágrimas (1956), Los motivos de Caín (1957), Los errores (1964) y El apando (1969). De los libros de cuentos: Dios en la tierra (1944), Dormir en tierra (1960), Material de los sueños (1974). Israel (1947), La otra (1949), en colaboración con Roberto Gavaldón. El cuadrante de la soledad (1950) y Nos vemos en abril son obras de teatro. Escribe los ensayos: México 
de Felipe Cazals ${ }^{3}$ (1975), transposición fílmica de la novela, constituyen antecedentes directos de la tendencia señalada anteriormente y forman parte del diálogo entre los textos actuales y los anteriores.

La novela corta El Apando, del mexicano José Revueltas, fue publicada en 1969 y escrita durante uno de los períodos en que el autor estuvo preso en la cárcel de Lecumberri (conocida como "El Palacio negro"), debido a su activa participación en el Movimiento Estudiantil del 68 mexicano. Figura polémica, Revueltas fue comunista y fue expulsado del partido, participó de la Liga Espartaco y del Partido Popular y nunca dejó de ser un militante revolucionario.

José Revueltas podría considerarse un teórico de la memoria a través de la ficción; su escritura no se entiende sin unir la experiencia política -no con la historia contada en la novela y el relato-, sino con la concepción de la novela o el "relatar", incluyendo a los guiones de cine y al drama. Sus textos reflejan una sana inconsistencia a veces, y se convierten en "ensayos", en el sentido de trabajar formas que van cercando al realismo, con la intromisión de largos pasajes casi propiamente "ensayísticos" en algunas obras. Revueltas disuelve las fronteras de los géneros literarios y configura una poética que la crítica no fue capaz de descifrar con facilidad en su época. Al morir, se afirmó que había muerto el último de los "realistas", dice Evodio Escalante.

No contentos con haberle dado el trato, preferente, eso sí, de perro equivocado -el perro de la heterodoxia que orina fuera de tiempo y de lugar-, ciertos críticos han insistido en descalificar la literatura de Revueltas por el delito de ubicarse no en las tierras fecundas de la vanguardia, sino en los sórdidos habitáculos de un realismo que ya

una democracia bárbara (1958), Ensayo sobre el proletariado sin cabeza (1962), El conocimiento cinematográfico y sus problemas (1965), Apuntes para una semblanza de Silvestre Revueltas (1966) y Cartas intimas y escritos de Silvestre Revueltas (1966). Al morir trabajaba en dos obras de ficción: Hegel y yo y El tiempo y el número.

Felipe Cazals nace en 1937 en Guéthary, Francia. Fundó, con Arturo Ripstein, Rafael Castañedo y Pedro F. Miret, el grupo Cine Independiente. Su primer filme importante es Emiliano Zapata, luego vendrán El jardín de tía Isabel (1971), Aquellos años (1972), Los que viven donde sopla el viento suave (1973), Canoa (1975), El apando (1975) y Las Poquianchis (1976). En la década del ochenta filma Rigo es amor (1980), El gran triunfo (1980), Las siete cucas (1980), Bajo la metralla (1982), Los motivos de Luz (1986), El tres de copas (1986), La furia de un Dios (1987), Burbujas de amor (1990), Desvestidas y alborotadas (1990), Los niños de Moravia (1997), Su alteza serenísima (2000), entre más de treinta filmes. Su último filme es Chicogrande, de 2009. 
dio todo lo que había de dar, y que, por lo mismo, ha perdido tanto su razón de ser como su actualidad" (Escalante 11).

El filme El Apando (1975), hipertexto (Genette 1989) en esta relación, fue realizado por Felipe Cazals y con guión del mismo Revueltas y del escritor José Agustín. Cazals ha sido conocido como el cineasta de los excesos o "cineasta de la crueldad", y su centro suele ser una descarnada crítica del imaginario de lo nacional mexicano. Cazals introduce una temática política y social que inscribe realidades ocultas del país, al menos para la industria cinematográfica mexicana. Cineasta que escapa de los cánones del mercado, contrario al espíritu conservador y moralista, introduce en el cine las capas medias, y en particular, el mundo de los bajos fondos y la marginalidad social.

En las dos versiones de El Apando se exhibe una puesta en crisis de los fundamentos de la racionalidad y sus correlatos totalizadores en varios niveles, aspectos que constituyen el centro de este artículo: la escenificación de la perspectiva óptica del sujeto geometral, la crítica del discurso tradicional de la nación y el planteamiento del encierro carcelario como extensión de la cárcel que es el mundo. Mediante diversas estrategias discursivas y visuales se propone una profunda crítica social de la marginalización y del sistema sociocultural, a partir de la puesta en escena del mundo de la droga y la violencia.

\section{EL SUJETO GEOMETRAL FALLIDO O LA PUESTA EN CRISIS DE LA MIRADA TOTALIZADORA}

Polonio, Albino y "El Carajo", tres delincuentes y adictos a las drogas, se encuentran en la prisión, aislados en la celda de castigo conocida como "el apando". La celda cuenta con un postigo destinado a introducir los alimentos y por el que los presos pueden sacar solo la cabeza y ponerla de lado, como en una bandeja, para mirar hacia afuera. Albino y Polonio son visitados por sus compañeras, las que son sometidas a inspecciones corporales abusivas por las carceleras con el fin de impedir que introduzcan drogas. En cambio, "El Carajo", un sujeto contrahecho, cojo, tuerto y débil, es visitado por su madre, una mujer mayor de rasgos indígenas, cuyas características la eximen de la inspección. En ese contexto, los tres presos traman un plan para lograr que la droga les sea enviada oculta en la vagina de la madre de "El Carajo", y para ello las dos mujeres de los presos deben armar un escándalo que desvíe la atención. Finalmente, el plan fracasa, la madre no entrega la droga 
y se produce una sangrienta pelea entre los dos presos y los guardias, y "El Carajo" termina denunciando a su propia madre.

La novela El Apando es un texto de 56 páginas, sin separación de capítulos, sin puntos aparte ni sangría; se presenta como un solo bloque escrito en continuidad. Esta estructura es gobernada por un narrador omnisciente que está fuera de la historia, pero que describe y valora desde la perspectiva de un preso más y que utiliza el lenguaje carcelario-mexicano y términos que pertenecen al léxico cinematográfico. Es una conciencia crítica y subjetiva, cuyo centro es la observación, descripción y traducción de las acciones, pensamientos, sensaciones de los personajes y de lo que sucede bajo su mirada vigilante.

La cabeza hábil y cuidadosamente recostada sobre la oreja izquierda, encima de la plancha horizontal que servía para cerrar el angosto postigo, Polonio los miraba desde lo alto con el ojo derecho clavado hacia la nariz en tajante línea oblicua, (...) Uno primero y otro después, los dos monos vistos, tomados desde arriba del segundo piso por aquella cabeza que no podía disponer sino de un solo ojo para mirarlos (...)" (Revueltas, El Apando 12).

La película, que conserva el título de la novela, no es el simple traslado de la historia y las acciones del texto literario, sino un proyecto de "traducción" de las estrategias narrativas centrales de la novela, en particular, de la mirada del narrador totalizante y la disposición sin pausas de la novela. La estrategia central, y la que dio origen a nuestra lectura, es una modalidad técnica que no es fácilmente notada por el espectador, una forma poco habitual: la cámara está fija durante todo el filme (excepto en la secuencia final). No hay movimiento de la cámara que provoque diferentes encuadres, sino una sucesión de planos. Los cambios se producen en el movimiento de la realidad profílmica (Souriau 1953). Esta política de lo visual es el principio que estructura ambos relatos -novela y filme-, una configuración que pone en juego las formas de la perspectiva visual y con ella las formas de la configuración del sujeto en la modernidad y en la sociedad contemporánea. El cómo se ve o se mira, cómo podemos ver, cómo debemos ver y desde dónde, son las normas que aprisionan al sujeto según la perspectiva del sujeto geometral ${ }^{4}$.

4 Jacques Lacan concibe el sujeto, en aproximación al "sujeto geometral", como correlato del sujeto cartesiano. En Los cuatro conceptos fundamentales del psicoanálisis 
El sujeto geometral es la resultante de la ubicación en un punto focal a partir del cual se proyectan los rayos luminosos, y ante el que el mundo se ofrecería como un puro espacio cuantificable. Se trata de una subjetividad y una psicología derivadas de la idealización racionalista del principio óptico de la perspectiva, en los términos de Erwin Panofsky ${ }^{5}$, quien remite a la concepción de Durero para entender la visión espacial, perspectiva desde la que son representados no solo objetos específicos o cosas, sino donde la totalidad del cuadro se transforma en una ventana a través de la cual nos parece estar viendo el espacio. Allí, la superficie material en relieve o pictórica sobre la que aparecen las formas de las figuras o cosas dibujadas es negada como tal y transformada en un espacio unitario y total, en el que se comprehende todo lo que en él figura, por lo que no importa si esta proyección es determinada por una impresión inmediata sensible o por una construcción geométrica que puede ser más o menos "correcta".

Esta visión de la perspectiva implica dos consecuencias importantes: que se mira a través de un ojo único e inmóvil, y que la intersección plana de la pirámide visual habría de considerarse como la reproducción de nuestra imagen visual. Evidentemente, estas hipótesis representan una abstracción de la realidad, especialmente en el segundo caso, pues la estructura de un espacio de esta naturaleza sería infinito, constante y homogéneo, y se opone a la del espacio psicofisiológico, en el que no es posible la infinitud o la homogeneidad.

La finalidad de la perspectiva exacta es transformar el espacio psicofisiológico en un espacio matemático, y se trata, por lo tanto, de la oposición entre el sujeto geometral y el sujeto psicofisiológico. Si la perspectiva es la construcción de una imagen en función del punto de vista del observador, el perspectivismo, como concepción filosófica, supone que toda representación es dependiente del sujeto que la constituye. Pero, sin embargo, el límite de dicho sujeto es

señala: "en la misma época en que la meditación cartesiana inaugura en su pureza la función del sujeto, se desarrolla una dimensión de la óptica que, para distinguirla, llamaré geometral". 92 (Seminario Los cuatro conceptos fundamentales del psicoanálisis. Ed. Paidós, Barcelona, 1987). No hemos ahondado en este artículo en las concepciones lacanianas acerca de la mirada y la visión, que, sin duda, forman parte también de la teoría del Estadio del Espejo, pues nos desviarían, de momento, de nuestro objetivo.

Erwin Panofsky (1999) propone una teoría que da cuenta del carácter simbólico de la perspectiva. Entre sus líneas de trabajo aborda la teoría plástica de Durero. Los argumentos sobre la perspectiva expuestos en este artículo se basan principalmente en sus concepciones. 
el cuerpo, pues, aún es su abstracción, la teoría de la perspectiva presupone un cuerpo uniforme que funcione mecánicamente, sin falla.

Si seguimos este razonamiento, la cámara cinematográfica es el punto focal, foco de la pirámide visual y por lo tanto, la representante del sujeto geometral. A su vez, los puntos de vista subjetivos de los personajes centrales, Polonio y Albino, serían puestos a funcionar idealmente como representantes del sujeto geometral en el discurso y configuración visual, a partir de la existencia de un emplazamiento visual dominante en la historia y que pretende controlar a los personajes: el postigo-guillotina del "apando" que obliga a ver con un solo ojo y desde un emplazamiento único. A su vez, los personajes centrales ven tal como ve el espectador, el que es obligado a mirar un plano fijo construido desde una cámara emplazada que no se mueve. Lo mismo ocurre en la novela con la operación del narrador, que a su vez, mira a los personajes y a través de los personajes.

A este trazado del sujeto geometral podemos agregar un dato interesante: el nombre de uno de los personajes, Polonio, nos conduce también al juego con la geometría. Entre los años 262 y 190 A.C. vivió Apolonio, más conocido como el "Gran Geómetra" (García López), Apolonio es el autor de los términos parábola, elipse e hipérbola, escritos en su libro Las cónicas, una introducción elemental a las propiedades básicas de los conos (el cono remite a un punto focal). En el nombre del personaje de los relatos novelesco y fílmico se omite la A y el personaje se llama Polonio.

La primera estrategia del filme, entonces, emerge a partir de la inmovilidad de la cámara y su confluencia con el sujeto totalizador, y al mismo tiempo, a partir de la "sujeción del sujeto" a un punto de vista único, en un espacio que se quiere también único y homogéneo; figura de subjetividades presas que son objeto para la visión determinante de ese Sujeto que a su vez está atrapado en el ojo único que preside la racionalidad occidental. El espacio paradigmático de ese sujeto es la cárcel.

Pero, el discurso no se detiene en esta figura, en los textos se realizará una segunda operación y esa operación es la que construirá la que hemos llamado "falla" de la propuesta totalizadora. Al reunirse todas las condiciones para la entronización del sujeto geometral y racionalista, el emplazamiento de la celda de castigo (el apando) separa la cabeza del tronco y produce un sujeto fragmentado, un sujeto no-perfecto. Si la cámara no se mueve y es una perspectiva única que formula una ventana-cuadro, al mismo tiempo existe algo que el ojo/cámara no puede hacer: controlar el cuerpo de los personajes que son los que introducen el movimiento (profílmico). Si la enunciación 
intenta ordenar el mundo desde la perspectiva totalizadora del Ojo, el filme refuta esa posibilidad mediante el argumento que opone a la totalidad la fragmentación; a la unidad la pluralidad, a lo completo lo incompleto. Y a la transparencia la opacidad.

Los cambios en el filme se producen mediante del movimiento de los personajes vistos como Otros respecto del sujeto geometral, y esto ocurre al interior de la imagen. La unidad ideal se rompe con la presencia de estos otros y como consecuencia el intento es fallido. Los personajes-otros se mueven, y además no pueden controlar/se, no controlan su cuerpo, pues está intervenido por lo no racional: la droga, el erotismo y la locura. En este contexto es que las perspectivas chocan, se oponen, y construyen la puesta en crisis de la vigencia de un sujeto totalizante.

En la novela, la operación se realiza a través del diálogo de los personajes y del discurso delirante y subjetivo del narrador que preside el relato, el que parece estar fuera de la historia narrada, sin embargo, pareciera ser un preso más y comparte el mundo y el estilo discursivo de los personajes. La perspectiva de un enunciador de tipo "fílmico", una cámara omnisciente que planea, asumida por el narrador en el texto literario es evidenciada en la historia en múltiples ocasiones, un ejemplo interesante es cuando se narra un momento de cesura del sonido, en el que solo queda presente el movimiento. Esto ocurre después del momento en que se produce la batahola creada por las mujeres de los presos y cuando la madre de "El Carajo" casi cae del segundo piso:

Volvió a reinar el mismo silencio de antes, pero ahora no solo por cuanto la ausencia de ruido y de voces, sino por cuanto los movimientos, movimientos en absoluto carentes de rumor, que no se escuchaban, como si se tratara de una lenta e imaginaria acción subacuática, de buzos que actuaran por hipnosis y donde cada quien, actores y espectadores, estuviese metido dentro de la propia escafandra de su cuerpo, presente y distante, inmóvil, pero desplazando sus movimientos fase a fase, por estancos, en fragmentos autónomos e independientes, a los que armonizaba en su unidad exterior, visible, no el enlace de una coherencia lógica y causal, sino precisamente el hilo frío y rígido de la locura. Algo ocurría en esta película anterior a la banda de sonido" (Revueltas, El Apando 5).

En una larga entrevista realizada por Jorge Ruffinelli a José Revueltas, el escritor habla de una "geometría enajenada", refiriéndose al final de la novela, 
secuencia en que los presos son atacados con largos tubos en una gran celda en la que quedaron atrapados a raíz de la trifulca que ellos y sus compañeras protagonizan, y en la que presos y gendarmes se golpean salvajemente:

Las rejas no son más que la invasión del espacio, y ahí hago una comparación: rejas por todas partes, rejas en la ciudad. Finalmente, cuando atraviesan los tubos, digo "la geometría enajenada" y remato toda la imagen que venía elaborando. El problema es un tanto filosófico, ontológico. La geometría es una de las conquistas del pensamiento humano, una de las más elevadas en su desarrollo. Entonces, hablar de geometría enajenada es hablar de la enajenación suprema de la esencia del hombre. No el ser enajenado desde el punto de vista de la pura libertad sino del pensamiento y del conocimiento. Esa es la tesis, si hay alguna (Ruffinelli, El apando: metáfora de la opresión 66) ${ }^{6}$.

\section{LA PUESTA EN ABISMO Y LA CÁRCEL UNIVERSAL}

La puesta en abismo7 es un "proceso mediante el cual los textos ponen en primer plano su propia producción, su autoría, sus influencias intertextuales, sus procesos textuales o su recepción”, señala Lucien Dällenbach (2001). En

6 Ruffinelli, en el artículo que contiene la entrevista, oscila entre dar primacía a los componentes políticos que rodean la novela, leyéndola como una "metáfora de la opresión política", elementos que examina a través de las cartas que Revueltas escribe desde la prisión, y los componentes estéticos que hacen que El Apando no sea un texto que narra circunstancias de lo político en el sentido tradicional. Ruffinelli se queda con la combinación de ambas, aunque de modo distinto al que proponemos (tomando en cuenta que entre su texto y la recepción actual distan treinta años), y señala que "lo que en un texto político se dice, en el texto literario se infiere. Ambos se conjuntan en la visión de un mundo opresivo, que corresponde a una misma época y a un mismo lugar" (Ruffinelli 42).

Al pie del texto en línea se indica lo siguiente: Seminario del CILL. "Este trabajo fue elaborado en forma colectiva durante el transcurso de un Seminario de Lectura Crítica del Centro de Investigaciones Lingüístico-Literarias de la Universidad Veracruzana. Intervinieron el maestro Jorge Ruffinelli (Uruguay)" (y estudiantes becarios). Se realizó entre mayo y julio de 1975. La parte que corresponde a la entrevista se grabó el 9 de agosto de 1975.

7 Existen otros conceptos aproximados al de puesta en abismo, como metaficción, autoficción, autorreflexividad, autoconciencia, entre otros, que enfatizan diversos aspectos y niveles en los que se produce esta operación y sus correspondientes sentidos, lo que indica una discusión muy interesante que excede este trabajo. La noción y operación de metaficción, en general, la de puesta en abismo, posee una amplia tradición desde la escuela anglosajona 
la novela y en el filme la estructura de puesta en abismo ${ }^{8}$ fractura la totalidad en varios niveles y produce efectos y sentidos intensos. Una de sus figuras funciona en torno del personaje "El Carajo", sujeto contrahecho, cojo y tuerto, lleno de cicatrices, sucio y maloliente que se corta para sangrar y ser llevado a la enfermería para conseguir droga, que llora, gime y se arrastra. Es absolutamente dependiente de la droga y de su madre, la que le lleva el dinero para que la compre. "El Carajo" es utilizado por los otros personajes para conseguir el ingreso clandestino de la heroína a través del contrabando en la vagina de su madre. En esta total dependencia de la figura materna, a lo que se suman sus rasgos físicos y mentales, "El Carajo" se configura como la negación del sujeto y la subjetividad, un no-sujeto que no ha abandonado la imagen especular del infans ${ }^{9}$ que reconoce su cuerpo solo en el cuerpo de

y francesa, entre los que se cuentan autores como Patricia Waugh, Linda Hutcheon, Jean Ricardou y Gérard Genette, por mencionar algunos.

Dällenbach diferencia entre tres formas de puesta en abismo: la duplicación simple, en los casos en que un fragmento de la obra refleja la totalidad, la duplicación al infinito: el fragmento incluye otro fragmento, el que a su vez incluye otro y así continúa. Y la duplicación aporística, cuando el fragmento incorpora la obra que lo incluye, impidiendo el avance a los demás niveles. En nuestro caso se trataría de una duplicación al infinito.

9 Jacques Lacan señala, en su texto sobre el estadio del espejo, que "la cría del hombre" en el momento en que es "superado en inteligencia instrumental por el chimpancé", entra en un proceso de comportamiento jubiloso a partir de la experiencia especular que provoca el reconocimiento de la que sería su imagen. (Lacan, El estadio del espejo como formador de la función del yo (je)). Al parecer, la identificación del infans con la imagen del espejo llega al punto en que no se puede desprender de ella. Esta imagen puede estar constituida por otro niño o por la madre. El caso es que en este momento el niño prefigura su imagen, lo que deviene en una separación de lo que parecía ser una unidad con la madre y va a provocar la entrada en el Edipo (cfr. 137 y ss. Lacan. Rifflet-Lemaire). Más allá de los múltiples aspectos que podrían ser discutidos a partir de este tema, me interesa solamente señalar la importancia simbólica que la entrada en los procesos de constitución del sujeto contemporáneo tiene para una lectura de la puesta en abismo que ocurre en los textos que nos ocupan. Por ello, remito a la síntesis que realiza Kemy Oyarzún, pues representa una lectura que compartimos, respecto de sus énfasis: (el Estadio del espejo) "Marca el parto de la diferencia, una suerte de protoconciencia en virtud del cual se introducirá el sujeto al Orden Simbólico y al Edipo. El lactante, separado de la madre, atraviesa por la experiencia del cuerpo fragmentado; se autoconcibe lleno de falencia, incertidumbre y desarticulación. Al contemplar su cuerpo en el espejo, experimenta el júbilo de verse -contrariamente a la auto-imagen desvalida- completo y grácil. Lacan considera que esa imagen especular es significativa para la formación y deformación de la auto-imagen. A partir del estadio del espejo, se construye una ilusoria unidad prostética que precipitará al niño hacia la cadena de objetos ortopédicos del deseo dependiente y objetalista. En adelante, el niño se insertará en una doble alteridad: a) la imagen completa en el espejo 
la madre; es un cuerpo que no puede decir "yo" porque no se ha producido la separación (en clave lacaniana se ubica en la entrada del Edipo). No ha habido parimiento, por lo tanto, la madre ha de proveer lo necesario para su sobrevivencia; el personaje aún está simbólicamente en el útero materno y termina él mismo convirtiéndose en una especie de sustituto de la droga, pues él es la imagen de la droga, por ello, los demás no pueden prescindir de su existencia, así como no pueden prescindir del vestigio de la Madre Universal, -la virgen de Guadalupe-(que se observa en una pintura deslavada en el patio de la cárcel) y la Madre mexicana, -la india-.

En esta puesta en abismo de la subjetivación, "El Carajo" remite a una suerte de involución del ser humano que ha sido figurado en la modernidad como sujeto libre y dueño de sí. El personaje está siendo emplazado desde la vagina (vehículo de la droga) a la placenta y al útero, en un recorrido inverso que penetra el cuerpo de la madre hasta retornar al lugar de encierro primigenio (además de la cárcel) del que no se puede salir o retornar. El producto es un sujeto con fallos en el lenguaje, en la voluntad, en el ejercicio libre y autodeterminado de las acciones. Sujeto que "nace" con una performance deficiente en el ejercicio de la razón y del cuerpo, ello se demuestra de modo ostensible en la figura eje que preside ambos textos: "El Carajo" no puede ver en forma estereoscópica: solo tiene ojo izquierdo, y la postura que exige el emplazamiento del postigo de la celda del "apando", en la que la cabeza tiene que descansar hacia uno de los lados, permite ver solo con un ojo, justamente el ojo ciego del personaje, por lo que no es apto para ejercer la vigilancia. La descripción literaria es elocuente:

En una de éstas fue cuando Polonio lo conoció, mientras "El Carajo", a mitad de uno de los senderos en el jardín de Enfermería, bailaba una suerte de danza semi-ortopédica y recitaba de un modo atropellado y febril versículos de la Biblia. Llevaba al cuello, a guisa de corbata, una cuerda pringosa, y a través de los jirones de su chaqueta azul se veían, con los ademanes de la danza, el pecho y el torso desnudos, llenos de bárbaras cicatrices, y bajo la piel, de lejanos y desvaídos tatuajes, (...) y la mirada legañosa de ojo sano tenía un aire malicioso, calculador, burlón, autocompasivo y tierno, bajo el párpado semi-caído,

del deseo edípico, romántico, metafísico (alteridad en el imaginario) y b) La imagen completa en el espejo del Otro, el Yo-Ideal internalizado (alteridad en el Orden Simbólico)”. (Oyarzún 172). 
rígido y sin pestañas. Flexionaba la pierna sana, la tullida en posición de firmes, las manos en la cintura y la punta de los pies hacia afuera, (...), para intentar en seguida unos pequeños saltitos adelante, con lo que perdía el equilibrio e iba a dar al suelo, de donde no se levantaba sino después de grandes trabajos, revolviéndose a furiosas patadas que lo hacían girar en círculo sobre el mismo sitio, sin que a nadie se le ocurriera ir en su ayuda. Entonces el ojo parecía morírsele, quieto y artificial como el de un ave. Era con ese ojo muerto con el que miraba a su madre en las visitas, largamente, sin pronunciar palabra. Ella, sin duda, quería que se muriera, acaso por este ojo en que ella misma estaba muerta (Revueltas, El Apando 19).

Un segundo sistema de puesta en abismo instituye a la cárcel como duplicación del sistema social y del mundo. Todos son presos, en la cárcel están presos los delincuentes, los gendarmes, los administradores. Todos son "monos" a través de la voz del narrador, sujetos idénticos y pasivos, tema con el que empieza la novela.

"Estaban presos ahí los monos, nada menos que ellos, mona y mono; bien, mono y mono, los dos (...) detenidos pero en movimiento, atrapados por la escala zoológica como si alguien, los demás, la humanidad, impiadosamente ya no quisiera ocuparse de su asunto (...) enjaulados dentro del cajón de altas rejas de dos pisos, dentro del traje azul de paño (...) dentro de su ir y venir sin amaestramiento, natural, sin embargo fijo, que no acertaba a dar el paso que pudiera hacerlos salir de la interespecie donde se movían, caminaban, copulaban, crueles y sin memoria, mona y mono dentro del Paraíso, idénticos, de la misma pelambre y del mismo sexo, pero mono y mona, encarcelados, jodidos" (Revueltas, El Apando 11).

Existe otra operación de puesta en abismo: a través de la involución hacia lo no-humano. Se distribuye en una serie que avanza desde el Mundo a México, a la cárcel, a la celda de castigo, al postigo y al ojo. En el filme, el sistema de encaje o repetición viene dado en este orden: la cámara, el cuadro, el campo y el punto de vista. Resultando un plano fijo que nos ubica a nosotros, los espectadores, como parte de la serie, pues estaríamos detrás de la cámara. De este modo se construye otro sistema que va desde la cámara al espectador y al mundo, y que reproduce (con nosotros) la serie de los "monos", pues estamos condenados a ver, aparentemente, lo que la disposición de la cámara nos permite. 
Estos dispositivos hacen del lector/espectador un sujeto en lucha con el principio de vigilancia universal y produce una dinámica de confrontación entre dos políticas visuales y dos políticas sociales; un par negativo y un par positivo. La primera política visual es la exhibición de la negación del movimiento de la cámara y el consiguiente envío a la pasividad de la observación de lo dado y la determinación fatal de la imposibilidad de la libertad. Por el lado de la historia contada - en ambos textos- no hay salida alguna y la posible resistencia se ofrece por el lado de la construcción textual. La puesta en escena de un intento de mirada totalizante que a través de los emplazamientos inscribe las políticas visuales de lo carcelario y al mismo tiempo visibiliza, mediante la puesta en abismo, una extensión que alude a lo universal y nacional del encierro como política social.

El segundo par en disputa, el par positivo, surge a partir de la confrontación con el par anterior y se realiza en la posibilidad de enunciar/denunciar textualmente la fatalidad a través de la libertad -aunque limitada- de movimiento de los sujetos/personajes, y especialmente mediante la propuesta que descansa sobre una crítica al realismo a través de la deconstrucción y exhibición de sus cimientos y su lógica, y por consiguiente, la posibilidad de resistencia. De este modo se construye una multiplicación de emplazamientos uno dentro del otro ${ }^{10}$.

\section{LA DENUNCIA A TRAVÉS DEL DISCURSO CARCELARIO}

El Apando, en sus dos versiones, es un texto representante de los discursos carcelarios. Una de las líneas más relevantes en este tipo de relatos tiene como centro los testimonios de encarcelamiento por razones políticas, causas sociales y situaciones de marginalidad y violencia en el marco de un correlato real o histórico. Los escritos de la cárcel o desde la cárcel como registro testimonial suelen narrar los padecimientos de un sujeto que ha vivido o que ha visto y experimentado la cárcel por dentro y ha sido parte

10 Uno de los componentes de la definición del concepto de puesta en abismo que emplea Pineda Botero señala que el proceso de creación se implementa a través de la técnica narrativa del encaje, y que la puesta en abismo constituye "una estrategia ideada por el autor para crear en el lector el efecto de una experiencia de lectura inescrutable" (Pineda Botero 1995, 25). 
de esa institución. Subyace una intencionalidad de denuncia de la violencia deshumanizadora del encierro, imagen radical de la violencia ejercida por la sociedad contemporánea.

La figura de la prisión representa el encierro absoluto como lugar donde se divide el adentro del afuera, y que se convierte en un obstáculo insalvable que suprime la interacción entre la prisión con su propia lógica interna y la sociedad que la construye. Es un lugar aislado que distorsiona la mirada de los que la observan desde afuera, convirtiéndose en un objeto difícil de descifrar por el hecho de que no se comparte un código común (Ríos Miranda), lo que a su vez proporciona un mundo propio a los que están adentro.

Si bien El Apando responde a un discurso carcelario, en él no existen víctimas inocentes ni héroes presos por rebeldía contra el sistema que funcionen como testigos o víctimas. En ese sentido, el narrador de El Apando da cuenta de una esencial ambigüedad: en apariencia está ausente de la historia, pero su lenguaje está contaminado de la jerga delictual, discurso de un preso-observador que "planea" o vuela sobre la prisión, observa y reflexiona elocuente y rabiosamente, incluso sobre el exterior e interior de los personajes y les cede la palabra. Un sujeto que conoce los códigos de ese micromundo. Una conciencia crítica involucrada.

En el mundo construido en la novela, la estructuración es presidida por un espacio siempre interior y carcelario regido por la hegemonía del postigo del "apando" (celda de castigo). El afuera es una especie de sueño en que los personajes y el narrador son sujetos delirantes que funcionan solo alrededor de la droga o el erotismo como únicas conexiones concretas con el afuera. Y, así como ocurre en toda cárcel, "el mundo externo pierde el sentido original que tenía para el sujeto ahora preso y el espacio interno se reconfigura" (Ríos Miranda), se resignifica, y es diferente de lo que "debería ser". La percepción de lo carcelario es de absorción y funciona desde adentro hacia afuera, con un lenguaje y una lógica interna.

El filme comienza con un recorrido que se origina en la calle que circunda la cárcel, espacio exterior desde el que se penetra en el mundo de la prisión (y de donde proviene la droga), gran concesión al afuera que en la novela está atenuada, y a lo que se añade la potencia visual que implica la exhibición de los carceleros o gendarmes en sus casas, en las que su comportamiento es el mismo que dentro de la cárcel.

$\mathrm{Ni}$ en la novela, ni en la película hay restricciones en la representación de la violencia, lo abyecto, la deshumanización. Desde esa visión interna el relato de la prisión incorpora un trasfondo de denuncia social claramente 
situado desde el inicio del filme y de la novela. En la película, entre el primer plano general de la prisión y la posterior mostración del interior de la cárcel, aparece un texto verbal -un cartel-, que dice que en 1968 José Revueltas sufrió cárcel por "sus convicciones" y que a partir de allí escribió El Apando. Este mensaje aporta un marco de interpretación que propicia una lectura demarcada de antemano, conduciendo a una recepción localizada que "contamina" la ficción con el registro documental a través de la asociación del filme a la biografía del autor y su militancia y acción política. Se ejecuta una operación que desplaza el texto fílmico hacia un registro realista de denuncia. En la novela, por su parte, se inserta una dedicatoria, que si bien fuera de la historia, es parte del discurso: "A Pablo Neruda", escrita en agradecimiento a las gestiones que realizó el poeta para la liberación de Revueltas mientras estuvo preso. Este texto introduce el mundo no solo literario y personal, sino político, a través de una figura de innegable significación para el pensamiento de izquierda latinoamericano de los años sesenta. Finaliza la novela con una inscripción que da cuenta del lugar en que el texto fue escrito: "Cárcel preventiva de la Ciudad. México, Febrero-Marzo 1969” (Revueltas 15). La función que cumplen ambos textos es similar y remite a los procesos políticos que suceden en México y América Latina en ese período.

Una segunda fractura importante que conduce hacia el fondo de denuncia se realiza mediante la introducción de la televisión, en una secuencia en la que el gendarme-mono aparece con su familia al interior de su casa-celda viendo la pantalla. La imagen que observan en la televisión es la de un hombre vestido de charro, atuendo clásico de los cantantes de música ranchera. La vestimenta, la actitud y el diálogo del charro entrevistado representa la figura arquetípica, fosilizada, comercial y canónica del varón del México de los años treinta y cuarenta. Figura ideológica marcada por la transnacionalización y la exportación del exotismo de lo mexicano massmediático, y el relato plasmado en el cine de rancheras de la época de oro del cine mexicano, cimiento de la industria cinematográfica del país.

Las películas de este género cinematográfico, configurado discursivamente como un relato clásico de acuerdo a las pautas del cine hollywoodense, combinan comedia, melodrama y musical y se orientan a instalar un imaginario nacional y nacionalista que resulta excluyente de las diferencias entre culturas, clases y sujetos. Porta una función eminentemente homogeneizadora y pacificadora a través de finales felices que permiten trascender las diferencias.

Según R. Stam, los géneros operan para establecer el orden social o para instalar la integración social. En este caso se cumple con las dos, pues el 
género de las rancheras mexicano forma parte de los discursos patriarcales y familiaristas en los que los roles de los varones y mujeres están determinados de antemano, y en que la familia y la religión funcionan como instituciones hegemónicas y ordenadoras de la sociedad latinoamericana. Una construcción de la nación-familia a partir de la pacificación de los conflictos a través del relato familiar, folletinesco y sus figuras. Las imágenes de la televisión en el filme están enmarcadas por la puesta en escena de la familia del gendarme. Secuencia en que el gendarme llega a la casa, su mujer está planchando, no se hablan, le arroja unos billetes arrugados, le agarra violentamente las nalgas, toma una cerveza y mira la televisión, mientras los niños chillan y se dan golpes. Ello se contrapone con el diálogo del charro entrevistado en televisión, quien habla de las canciones mexicanas y las describe como "muy mexicanas", para todas las edades, y afirma que su concepción proviene del hecho de que él no es un "intelectual", pues para eso "le sobra mucho corazón". Charro en decadencia y decadencia del género del melodrama rancheril, construido en el filme mediante el contraste, y por extensión, decadencia de la nación como esencia estereotipada y excluyente.

Para Carlos Monsiváis, el discurso de la identidad nacional en México se mantiene desde los medios de comunicación (244), orientado a un espectador al que siempre se trata como a un "menor de edad", en el marco de una cierta "unidad nacional producida por el cine" $(220)^{11}$. En la música ranchera y el charro se concentra la popularidad de la imagen nacional creada por los discursos hegemónicos por medio de la imagen del varón como "macho". Todo ello es subvertido en el filme y en la novela mediante contrapuntos entre el imaginario que el cine de rancheras convoca y los contenidos y estrategias discursivas de El Apando; por un lado, la familia ideal, y los héroes populares (los charros), alegres y sensibles al mismo tiempo que pendencieros y machistas, ambiente rural idealizado, relato clásico hollywoodense, y por

11 Monsiváis realiza una aguda crítica a la televisión y a ciertos programas de éxito. En particular, en el capítulo "Lo entretenido y lo aburrido. La televisión y las tablas de la ley", liga la televisión, la derecha y la Iglesia Católica: "Inútil disminuir el papel de la televisión en los proceso de identidad nacional (según sus adversarios, el apocalipsis, donde uno, con tal de respetar a sus ancestros, se ve obligado a repetir los gestos por toda una eternidad) y de integración a la sociedad de consumo (el Juicio final según sus oponentes, donde uno renuncia a la esencia con tal de salvar la contingencia)". (Monsiváis, Aires de familia 211). Carlos Monsiváis pasa revista a toda la cultura de masas, el cine, la radio, la música, y se refiere al "macho" mexicano y al imaginario que lo rodea en el capítulo "Mexicanerías: ¿Pero hubo alguna vez once mil machos?" (Escenas de pudor y liviandad 103). 
el otro, una construcción textual compleja en el filme y la novela, una puesta en escena de la incomunicación y la violencia, personajes adictos a la droga y delincuentes, y espacio de la prisión.

La casa, el comedor y la "caja de televisión" son otros encierros carcelarios que se suman a la estructura de puesta en abismo, cajas chinas que encierran las costumbres del ciudadano latinoamericano. La clave de la función política dentro de esta imagen es reforzada mediante la focalización de lo nacional a través de una construcción sentimental y ulteriormente fracasada: el melodrama del amor perdido o el conflicto pre-edípico de "El Carajo", sujeto no-parido que quiere seguir siendo uno con la madre, previo al proceso de individuación, y que no ha accedido a la cadena de sustitución del objeto perdido. En una entrevista, Revueltas señalaba:

Entre los varios problemas de El apando, el de El Carajo y su madre es un problema claustral, de claustro materno. El es un ser que está en la cárcel como dentro de un claustro materno, todavía no parido. Su ligazón con la madre es una ligazón de amor y odio, amor y desprecio, que viene a sintetizarse al final (Ruffinelli, El apando: Metáfora de la opresión 61).

En la película, en el contexto de la caracterización de "El Carajo", se insertan dos planos: se aprecia en lo alto de la pared la imagen de la virgen de Guadalupe, desgastada y raída. A ella se une un personaje de rasgos homosexuales y la música de fondo es una canción ranchera-melodramática como es habitual-, que dice: "la culpa de mis vicios / una mujer ingrata / porque no tuve plata / para comprar su amor / La pobre de mi madre / es la que está sufriendo / dice que soy la causa / de todo su dolor".

Puesta en crisis nuevamente del nacionalismo patriarcal, puesta en escena del conflicto primigenio: la constitución del sujeto en clave psicoanalítica. "El problema de la madre en México es un problema de orfandad; tan así que para sustituir la devastación, el despojo de que la Conquista hizo víctimas a los aborígenes, surge la virgen de Guadalupe, la Madre Colectiva, la MadreNacional", explica José Revueltas (62).

Hacia el final del filme, una vez que la salvaje pelea entre presos y celadores ha llegado a su fin y que "El Carajo" ha denunciado a su madre, la secuencia final muestra la imagen del cuerpo de la madre de "El Carajo"; la imagen es acompañada de un silencio casi absoluto, perturbado solamente por el llanto de un recién nacido. Pero, además, el cuerpo de la madre es mostrado a través 
del movimiento de la cámara, que la recorre desde abajo hacia arriba, en un travelling vertical, liberando a la cámara de su quietismo.

Finalmente, lo que se ha producido es una disputa interna en el filme y la novela, no hay happy end ni salidas del encierro del mundo, pero sí una visión desenmascaradora de las mitologías de la nación y de la madre universal que sustituyó la devastación de la conquista, una puesta en crisis del poder del sujeto moderno, de las visiones totalizadoras y la racionalidad occidental y, al mismo tiempo, una subversión de los códigos realistas del relato fílmico y el relato literario, instalando una denuncia de la opresión y la violencia del sistema social contemporáneo. Los relatos nos introducen en lo que será, décadas más tarde, la representación del mundo del narcotráfico y las consecuencias de la globalización económica en América Latina.

\section{BIBLIOGRAFÍA}

Dällenbach, Lucien. El relato especular. Madrid: Visor, 2001.

Escalante, Evodio. “Los desengaños del realismo”. La Gaceta http://www.fondodeculturaeconomica. com/subdirectorios_site/gacetas/nov_2014.pdf

García López, Alfonsa. Cónicas y otros lugares geométricos. Universidad Politécnica de Madrid. http:// oa.upm.es/4936/2/INVE_MEM_2008_60535.pdf

Genette, Gérard. Palimpsestos. La literatura en segundo grado. Madrid: Taurus, 1989.

Figures III. Barcelona: Lumen, 1989.

Hutcheon, Linda. Narcissistic Narrative, the Metaficitional Paradox. New York: Methuen, 1980.

Lacan, Jacques. "El estadio del espejo como formador de la función del yo (je) tal como se nos revela en la experiencia psicoanalítica." Escritos 1. Buenos Aires: Siglo XXI, 1988.

Lacan, Jacques. Los cuatro conceptos fundamentales del psicoanálisis. Barcelona: Paidós, 1987.

Oyarzún, Kemy. Poética del desengaño. Santiago: Lar, 1989.

Rifflet-Lemaire, Anika. Lacan. Barcelona: Edhasa, 1971.

Ricardou, Jean. Problèmes du noveau roman. Paris: Editions du Seuil, 1967.

Panofsky. Erwin. La perspectiva como forma simbólica. España: Tusquets editores, 1999.

Pineda B., Álvaro. Del mito a la posmodernidad. La novela colombiana de finales del siglo XX. Bogotá: Tercer Mundo, 1994.

Monsiváis Carlos. Aires de familia. Cultura y sociedad en América Latina. Barcelona: Anagrama, 2000.

Escenas de pudor y liviandad. México: Grijalbo, 1981.

Revueltas, José. El Apando. México: Ediciones Era, 1969. 
Ríos Miranda Alejandro. Laicosos: trama de subjetividades no convencionales (los laicosos y su mundo). http://www.conductitlan.net/70_subjetividades.pdf(visitado en junio de 2015)

Ruffinelli, Jorge, et al. El apando: Metáfora de la opresión. Centro de Investigaciones Lingüístico-Literarias. http://148.226.12.104/bitstream/123456789/7224/2/19752P40. pdf (visitado en septiembre de 2015)

Souriau, Etienne. L'univers Filmique. Paris: Flammarion, 1953.

Stam, Robert. Teorías del cine: una introducción. Barcelona: Paidós, 2001.

Waugh, Patricia. Metafiction. The Theory and Practice of Self-Conscious Fiction. New York: Methuen, 1984. 